\title{
Design and Fabrication of Pneumatic Can Crushing Machine
}

\author{
S.K. Bello ${ }^{1}$, G.G. Bajela ${ }^{1}$, S.B. Lamidi ${ }^{1}$ and S. Oshinlaja ${ }^{2}$ \\ ${ }^{1}$ Department of Mechanical Engineering, Lagos State Polytechnic, Ikorodu \\ ${ }^{2}$ Department of Civil Engineering, Lagos State Polytechnic, Ikorodu \\ Nigeria
}

\begin{abstract}
This paper is based on the design and fabricate of a pneumatic can crusher that will reduce to the smallest possible amount of the volume of aluminum cans by $70 \%$. The can crusher is made up of various parts containing parts such as a lever, base frame, can bin, piston cylinder arrangement, chain sprocket mechanism and bearing. The inspiration behind this design came from the wastages in eateries, canteens of big companies where people gather and consume a lot of canned beverages. Thus, it makes sense that there should be an easy way to dispose of used cans properly during large social gatherings. The Can Crushing machine works with the help of pneumatic single acting cylinder. The machine is portable in size, and as such is easily transportable. Most companies find it difficult to dispose of their used cans in hotels and canteens and to create enough storage space that is required. This paper deals with the operations, the design and structural analysis of can crusher. A Can crusher is a device to reduce large material object into a smaller volume. The crusher reduces the size or change the form of waste materials so that they can be disposed off or recycled easily. The Can crushing machine is designed to crush aluminum waste cans by $80 \%$. reduction in volume. It is used primarily to ease transportation of aluminum waste for recycling purposes. The machine is designed to smash an empty can of diameter $65 \mathrm{~mm}$ and height $120 \mathrm{~mm}$ to height of between $25 \mathrm{~mm}$ to $30 \mathrm{~mm}$. It uses compressed air for its operations with the following component parts: pneumatic cylinder, solenoid valve, control unit and hoses. The cans are fed into the hopper and the cans travel in an orderly manner through the chute into the crushing chamber. The air compressor through the pneumatic cylinder supplies the required crushing force. The crushed cans drop through the created space into the collection tray below the crushing chamber.
\end{abstract}

Keywords: Belt Pulley, Cans Components, Crushing machine, Quick return mechanism.

\section{INTRODUCTION}

When people footstep the cans after finishing their drinks, the can does not look symmetrically flat and it looks messy. This condition sometime makes cans produce sharp edges which could be harmful or injurious to people. Furthermore, people always throw cans anywhere. These conditions pollute the environment. So this design is used for crushing cans as flat as possible, try to reduce time and cost as well as eliminate the sharp edges.

A can crusher is a machine designed to reduce large solid materials into a smaller volume, or smaller pieces. Crushers may be used to reduce the size, or change the form, of waste materials so they can be more easily disposed of or recycled, or to reduce the size of a solid mix of raw materials (as in rock ore), so that pieces of different composition can be differentiated.

The Can crushing machine which is fabricated incorporates the use of the "quick return mechanism" for crushing the cans one at a time in one stroke, i.e.; one can be crushed during the forward stroke of the piston. (Jayakumar 2011) ${ }^{[2]}$. This mechanism is most commonly used in shaping machines. The quick return mechanism is an inversion of the slider crank which converts rotary motion into reciprocating motion. All parameters related to the design aspects were considered and calculated. Various stress factors were considered and suitable tolerances and factor of safety was accordingly employed to reduce chances of failure and increase the life and durability of the machine. (Shadab. et al) ${ }^{[6]}$. Adequate care was also taken to ensure negligible slipping of the belt to achieve maximum efficiency. The objective of this project is to design and fabricate a can crusher which incorporates the use of "quick return mechanism". This can crusher can be used to crush aluminum cans of (200ml) for suitable disposal and subsequent recycling. The Quick return mechanism is a mechanical device which is used for crushing cans. The can crusher on crushing the cans reduces the size of the cans and hence create enough space to accommodate the waste.

This paper is centered on the design and fabrication of pneumatic Can crusher meant to reduce aluminum waste Cans, that will reduce the volume of aluminum by 80 percent. Can crushers be primarily used to reduce the size of cans for easy transportation of 
large volume for recycling. A Can crusher is defined as a device used for crushing aluminum Cans for easier storage in recycling bins thereby giving the needed extra space by reducing the size or the Cans.

The inspiration behind this design came from the festivals, wastage in, canteens of big companies that are involved in large parties where people gather and consume a lot of canned beverages. Thus this can crusher was created, with a portable and pneumatically operated mechanism. There are many designs of can crushers. Some of the designs are manual, pneumatic and hydraulic.

As Canned beverages, drinks and fruits are frequently consumed even in homes. These Cans do take up lot of space and transportation cost is also high for moving huge number of Cans from one place to the other. Even if people step on the tin after usage, it does not always like symmetrically flat and it looks messy and irregular. The act of crushing the Cans with our feet usually leads to sharp edges that can harm people. Furthermore. we tend to dispose these Cans badly, thereby leading to environmental pollution. Recycling aluminum requires only 5\% of the $\mathrm{C} 02$ emission as compared with primary production. More than 100 billion aluminum cans are sold every year, but less than half of them are recycled. A similar number of aluminum cans in other countries are also incinerated. (Suryakant et al 2016) ${ }^{[10]}$ Aluminum Cans are some of the easiest materials to recycle. New drink Cans appear on the shelf just six weeks after recycling. The aim of this paper is to create a crushing device that reduces the volume of aluminum cans to about $80 \%$ of the original size, of cans with low cost and also reduce the rate of environmental pollution (Shadab el al 1997) ${ }^{[6]}$. More so, is aimed at fabricating a Can crusher that has storage to locate the Can after crushing

\subsection{Developmental Trend in Can Crusher}

The type of crusher used in modern day is a product of improvement and modification of simple components that make up the machine. These modifications arise as a result of research for better and more convenient and faster means of crushing empty beverage Cans. The development in the trend of Can Crushing device has gradually resulted to various types of Can Crushing devices ranging from the manual to the hydraulic and finally the pneumatic type.

\subsection{Industrial use of Can Crusher}

In the industry. crushers are machine that uss a metal surface to break or compress materials. Mining operations uses crushers commonly classified by the degree to which the fragment of the starting material. with primary and secondary crusher handling coarse materials and tertiary and quaternary crushers reducing ore particles to finite gradations. (Khurmi and Gupta 2009) ${ }^{[3]}$

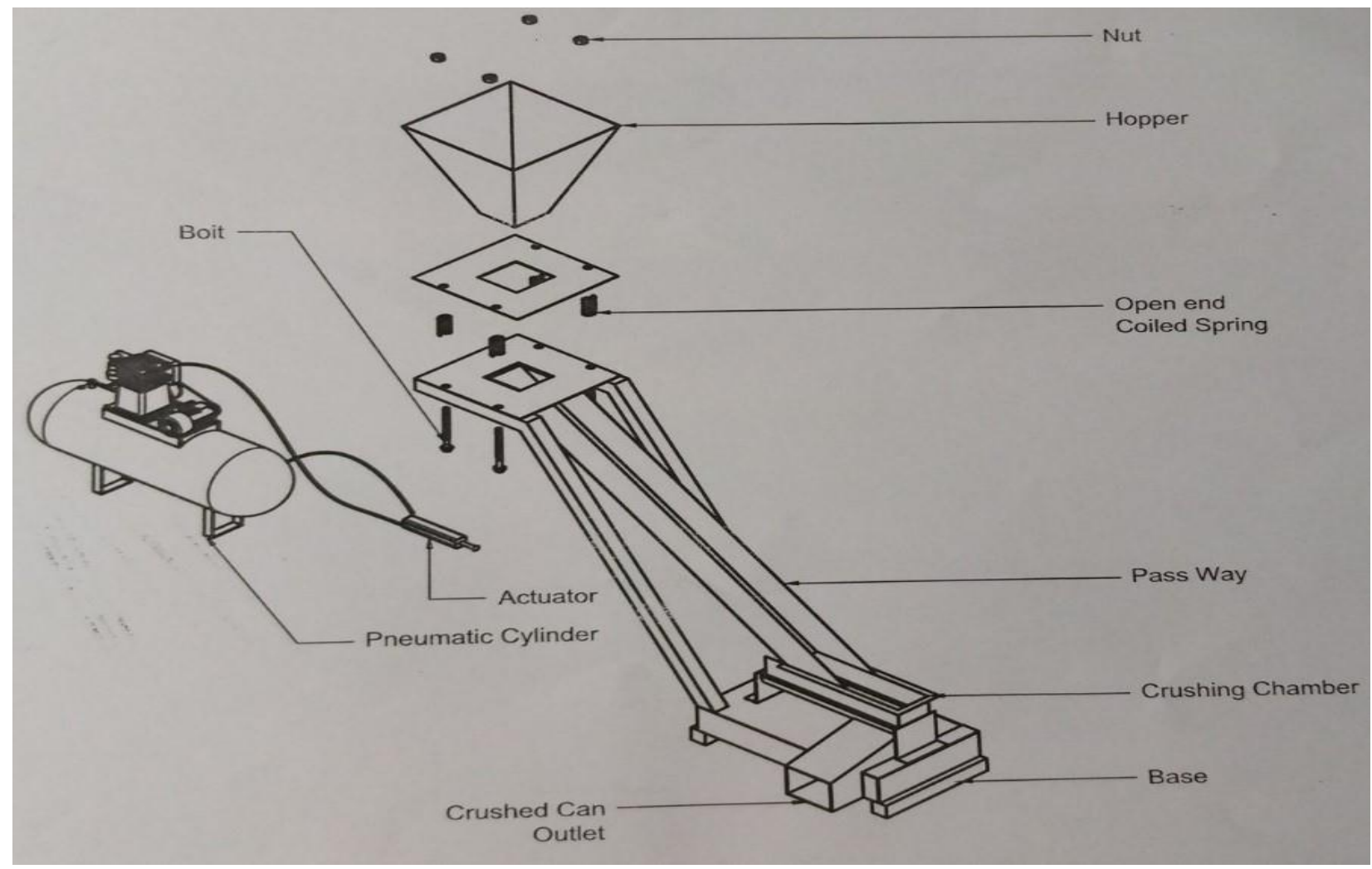

Figure 1: Exploded view of Can crushing machine. 
International Journal of Advances in Scientific Research and Engineering (ijasre), Vol 6 (10), October -2020

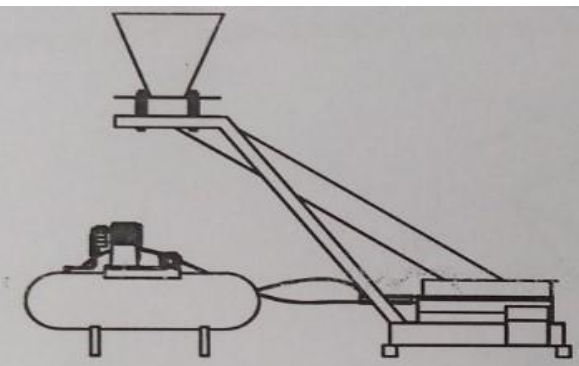

Front View

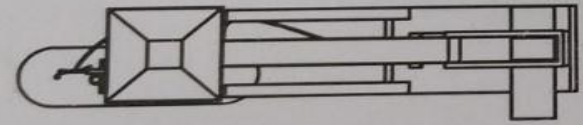

Top View

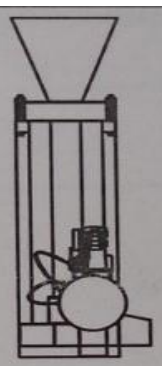

Side View

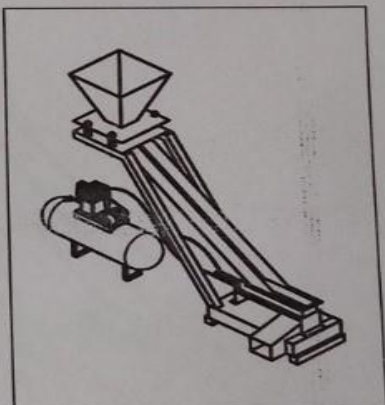

Figure2. Orthographic view of Can crushing machine in first angle projection

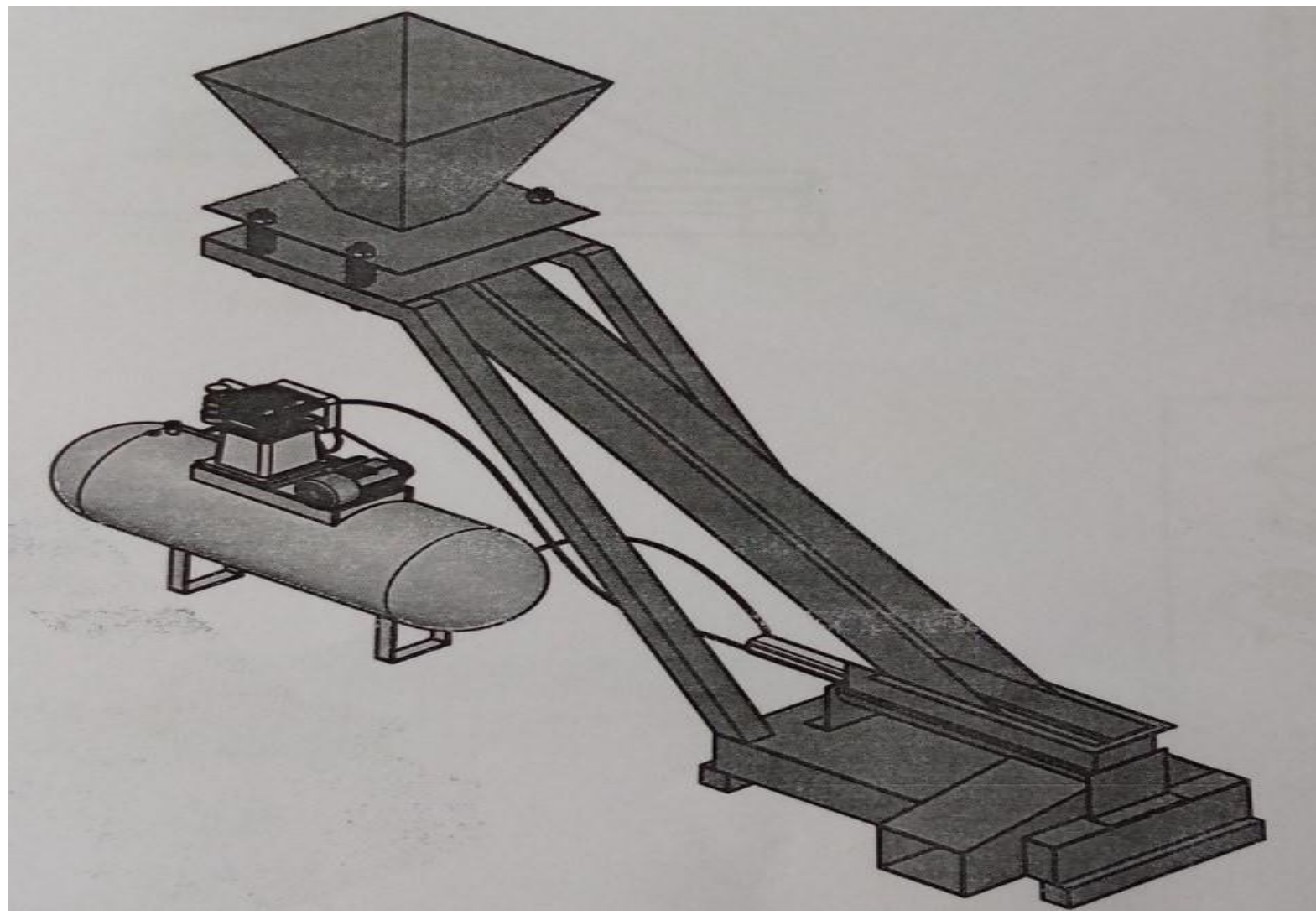

Figure3. Isometric view of Can crushing machine 
International Journal of Advances in Scientific Research and Engineering (ijasre), Vol 6 (10), October -2020

\section{3 TYPES OF CAN CRUSHER}

\subsubsection{Manual Can Crusher}

The manual can crusher is used for crushing Cans, and it requires manual efforts in order to reduce the size of the Can to the barest minimum. There are different ways formerly used in crushing Cans manually. These include the use of stones, heavy metal or hard wooden objects

1.3.2 Hydraulic Can Crusher: Hydraulic system of crushing cans is similar to the pneumatic system; the only difference is that hydraulic system uses hydraulic oil compared to pneumatic system which uses compressed air as the working fluid

1.3.3 Pneumatic Can Crusher: A pneumatic type of Can crusher uses compressed air as a working medium for power transmission. The system of operation is similar to that of hydraulic system except that the hydraulic system uses fluid. Air compressor converts the mechanical energy of the prime mover into mainly pressure energy of the compressed air

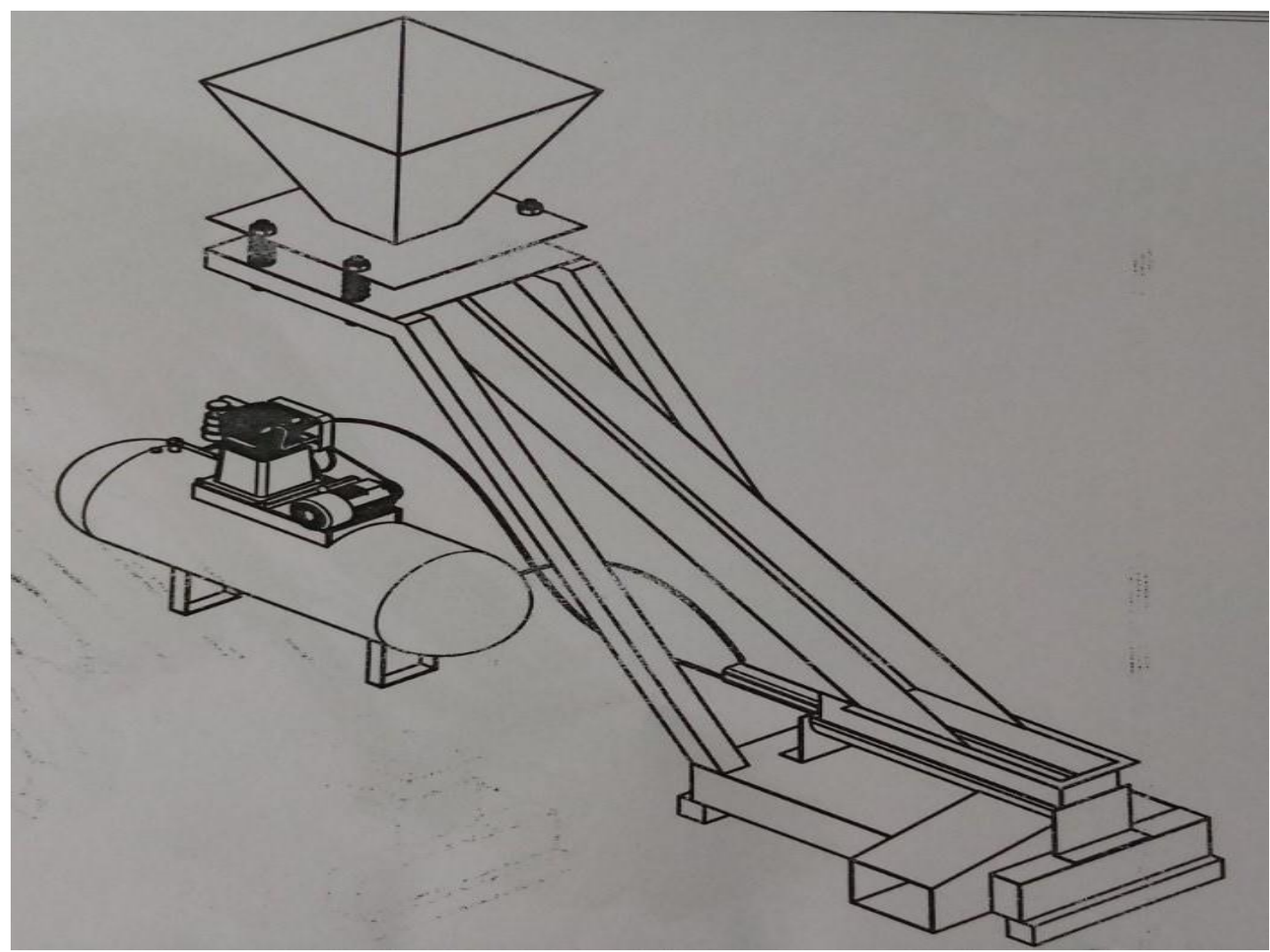

Figurel4. Isometric view of Can crushing machine

\subsubsection{Principles of operation of Pneumatic Can Crushing Machine}

This type of can crusher generally consists of a pneumatic system to drive a piston forward or reverse backward. When the piston is moved forward a plate which acts as a bore of the piston moves along with the piston and crushes the can. A groove that is created which allows the crushed cans to drop into the collection container at the bottom of the frame.

\subsubsection{MAINTAINENCE AND SAFETY -}

Maintenance - As a result of its continuous usage, the machine will undergo wear and tear of the mating and sliding components. Hence it requires maintenance. This process consists of the repairing and replacement of its component parts, called maintenance. 
International Journal of Advances in Scientific Research and Engineering (ijasre), Vol 6 (10), October -2020

Table 1.0 Test and monitor-for can crushing

\begin{tabular}{|c|c|c|c|}
\hline Test criteria & How tested & Expected result & Actual result \\
\hline Reliability & $\begin{array}{l}\text { M measuring size before and } \\
\text { after crushed }\end{array}$ & $\begin{array}{l}\text { The can will be crushed to } 70 \% \text { of } \\
\text { its original height }\end{array}$ & $\begin{array}{l}\text { The can was crushed to } \\
1.5 \text { ' in height }\end{array}$ \\
\hline Durability & $\begin{array}{l}\text { Open and close the drawer } \\
\text { of the bin that stores } \\
\text { aluminum can }\end{array}$ & $\begin{array}{l}\text { The aluminum can bin will slide in } \\
\text { and out with ease }\end{array}$ & $\begin{array}{l}\text { The aluminum can bin } \\
\text { slide with much ease }\end{array}$ \\
\hline $\begin{array}{l}\text { Bin can hold } \\
\text { over } 20 \text { cans }\end{array}$ & Load 20 cans in the chute & $\begin{array}{l}\text { All } 20 \text { can will be crushed one after } \\
\text { the other }\end{array}$ & $\begin{array}{l}\text { Bin could hold } 20 \text { cans } \\
\text { and still had some space }\end{array}$ \\
\hline Self-Loading & $\begin{array}{l}\text { Put cans into the self- } \\
\text { loading mechanism and they } \\
\text { will slide down }\end{array}$ & $\begin{array}{l}\text { The crusher will be able to self-load } \\
\text { appropriately without any } \\
\text { complications }\end{array}$ & $\begin{array}{l}\text { The self-loading } \\
\text { mechanism can hold cans } \\
\text { with about } 25 \mathrm{~mm} \text { space } \\
\text { at the top }\end{array}$ \\
\hline $\begin{array}{l}\text { Can must } \\
\text { end-up in bin } \\
\text { after } \\
\text { Crushing }\end{array}$ & $\begin{array}{l}\text { Crush a can to see if it falls } \\
\text { through the hole into the bin }\end{array}$ & The can will fall into the bin & $\begin{array}{l}\text { They will fall into the bin } \\
\text { with ease }\end{array}$ \\
\hline
\end{tabular}

\subsection{METHODOLOGY}

In designing and fabricating this tin can crusher, a flow of methods had to be used the design and crusher the tin. First of all, a process planning had to be charted out. (Soakakke 2008) ${ }^{[9]}$. This acts as a guideline to be followed so that, the final model meets the requirement and time. This would determine the efficiency of the Can crushing machine. Controlling and analyzing these steps are very important as each of them will lead to having an effective and efficient system. 
Flow

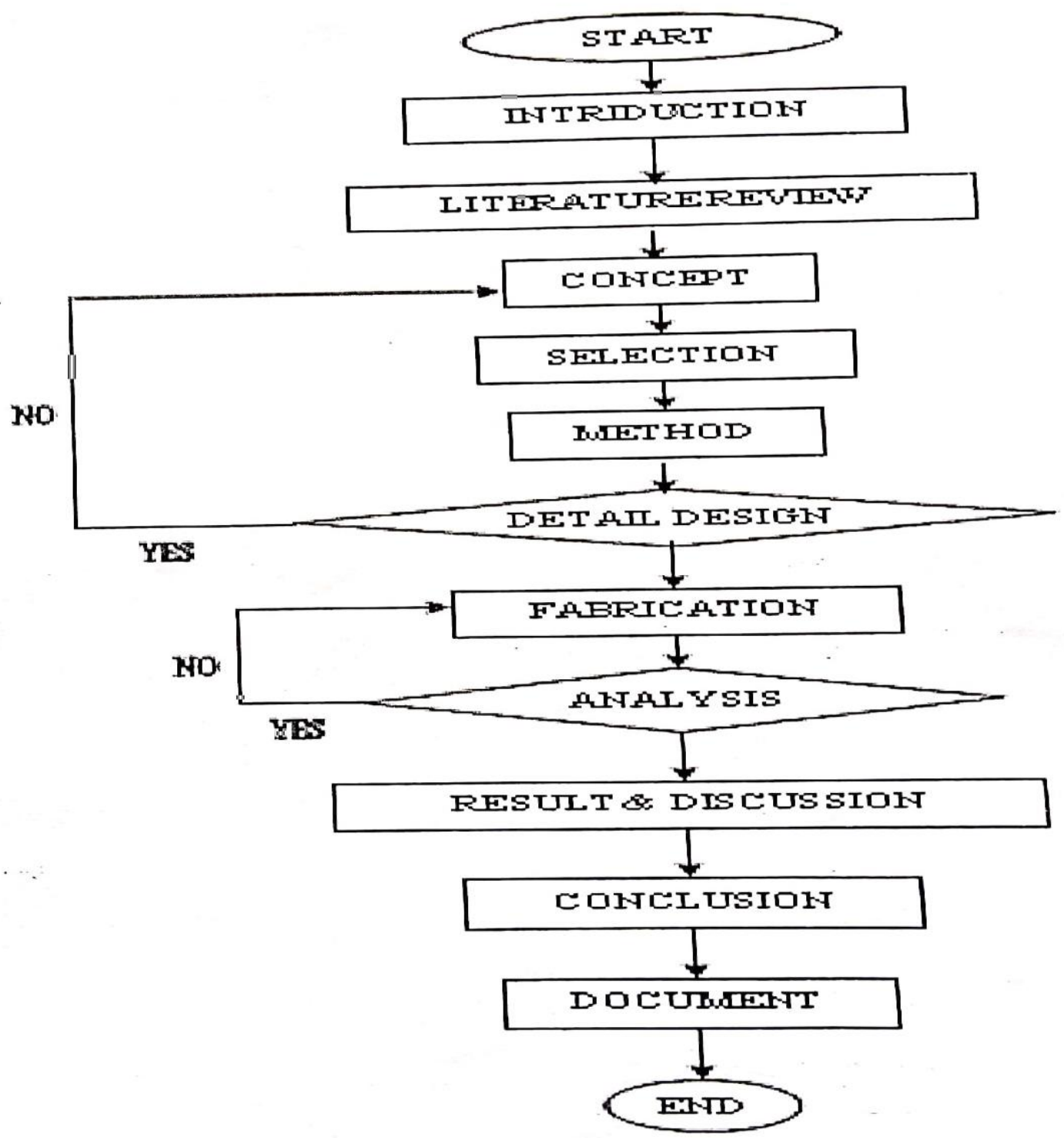

Fig 5: Flow chat diagram

The flow chart starts with the introduction to commence the process. Literature review on the title is done thoroughly covering all the aspect of the project. The medium for this research are via internet and books, in which case essential information related to the project is gathered for referencing. In conceptualization, few designs are done using the sketching which is then saved to be reviewed from one stage to the other. The sketching is the first step, then the designs and concepts are than reviewed and recalculated to fit the best dimensions and performance of recycle can crusher. However, the drawing using software is just a guideline to be followed to improve the can crusher (Shadab et. al) ${ }^{[6] .}$ After the draw is done, it proceeds to the project proceeds to fabrication process. The fabrication process involved cutting, welding, drilling, bending and others. After every process, the parts are check to make sure that the output of the process is in conformity with the product requirement. Then comes the analysis processes. In which case the can crusher will be tested to see if it fulfills the requirement such as easy to crush the can. Methods and process involve in this project include; joining using bending, welding, drilling, and cutting process. This project involves the process of designing the different parts of the crusher machine considering the forces and ergonomic factor for people to use. (Khurmi and Gupta 2009) [3].

In the design and fabrication of the pneumatic Can Crusher, the main aim is to study the complete design of semi-Automatic can crusher machine. In this design and calculation procedure parameters have been taken into consideration from design data Book, Thesis and, Journals.

In this paper we have developed a semi-automatic Pneumatic Can Crusher that can crush average Cans symmetrically as much as possible before the crushed cans will land in the collection bin. The design is environmentally friendly and uses simple working mechanism. The main aim of this machine is to crush an empty Can of diameter $60 \mathrm{~mm}$ and height of about $120 \mathrm{~mm}$. 
International Journal of Advances in Scientific Research and Engineering (ijasre), Vol 6 (10), October -2020

Can crusher calculation:

Can dimension $65 \mathrm{~mm}$ diameter $(32.5 \mathrm{~mm}$ in radius) and height $120 \mathrm{~mm}$.

volume of uncrushed can

$\mathrm{V}=\pi \mathrm{r}^{2} \mathrm{~h}$

$\mathrm{V}=\pi \times 32.5^{2} \times 120$

$\mathrm{V}=398196 \mathrm{~mm}^{3}$

volume of crushed can:

$\mathrm{V}=\pi \mathrm{r}^{2} \mathrm{~h}$

$\mathrm{V}=\pi \times 32.5^{2} \times 20$

$\mathrm{V}=66366.144 \mathrm{~mm}^{3}$

Percentage reduction in volume $=88 \%$

No of crushed Can be stored in the space occupied by an uncrushed Can $=6$

force required for crushing a can

The force required to crush a Can is about 2,300N.

Bore diameter of our pneumatic cylinder $(\mathrm{d})=60 \mathrm{~mm}(0.06)$.

We know; pressure $(\mathrm{P})=$ force/ Area $(\mathrm{A})$

Area $(43 w A)=\pi d^{2} / 4$

$3.142 \times 0.0036 / 4$

$=0.002828$

Pressure $(\mathrm{P})=\mathrm{F} / \mathrm{A}$

$=2300 / 0.002828$

$=813295.62 \mathrm{~N} / \mathrm{m}-$ approximately $8 \mathrm{bar}$

\subsection{RESULTS AND DISCUSSION}

The can crushing machine was tested and found to be quite effective and efficient in its operation.

It can crush between fifteen and twenty can per minute. It is very robust, and cost effective and can be readily available for Hoteliers and Proprietors of fast food outlets. The frame is made up of mild steel materials which made it very stable to withstand the crushing force and other auxiliary vibrating force. The machine has all it takes in terms of speed, reliability, durability and performance indicators.

\subsection{CONCLUSION}

The above design procedure is being adopted for the fabrication of fully automatic can crusher machine which will make the product durable for a long time as well as make it efficient. Thus, with the help of a functional design we can fabricate an

Table 2.1 MATERIAL SELECTION

\begin{tabular}{|l|l|l|l|}
\hline S.No. & \multicolumn{1}{|c|}{ Component } & \multicolumn{1}{|c|}{ Description } & quantity \\
\hline 1 & Hopper & Mild steel sheet 3mm thickness & 1 \\
\hline 2 & Strip quide & Mild steel sheet 3mm thickness & \\
\hline 3 & Crushing Chamber & Mild Steel sheet $8 \mathrm{~mm}$ thickness & $1 / 2$ \\
\hline 4 & Foundation & Mild Steel 11/2 & 1 \\
\hline 5 & Pneumatic cylinder & Double acting bore cylinder & 1 \\
\hline
\end{tabular}


International Journal of Advances in Scientific Research and Engineering (ijasre), Vol 6 (10), October -2020

\begin{tabular}{|l|l|l|l|}
\hline 6 & Solenoid valve & $5 / 2$ port device 3 way connection valve & 1 \\
\hline 7 & Air compressor & 2 Horse power 25litre tank capacity & 1 \\
\hline 8 & Control unit & 2 way press and 8.500 box & 1 \\
\hline 9 & Bolt and nuts & Size 17 & 1 \\
\hline 10 & Clip & Size 6 & 2 \\
\hline 11 & Paints & Blue & 3 \\
\hline 12 & Valve Port & Curve & 3 \\
\hline 13 & Valve port & $\frac{3}{4}$ blue hose & 5 yards \\
\hline 14 & Hose & & \\
\hline 15 & Transportation & & 3 \\
\hline
\end{tabular}

automatic can crusher machine to simply increase the number of cans to be crushed as well as to reduce the human fatigue involved. At the start of this project, our priority was to research can crushers and how they work, how to build them, and we had to make sketches of a frame, bin, and crushing mechanism. Once we had our design picked out, we were ready to go through and make all decisions that were necessary to finish and complete our project successfully. ( Singh Pankaj et al) ${ }^{[8]}$. In building the can crusher, we started with the component parts and handle one after the other until we successfully complete them all. We saved the building of the crushing mechanism for last because we knew it would take the longest and most complex to build.

\section{REFERENCES}

1. Jayakumar V. - "KINEMATICS OF MACHINERY” (2011)-5th Edition-Lakshmi Publications, Definition and basic concepts Quick return mechanism-pp1.42.

2. KHURMI R.S.AND GUPTA A 'TEXTBOOK OF MACHINE DESIGN'

3. MET's Institute of Engineering, Bhujbal Knowledge City, Nashik, Maharashtra, India.

4. RESEARCH (IJCESR) ISSN (PRINT): 2393-8374, (ONLINE): 2394-0697, VOLUME-4, ISSUE-7, 2017 12

5. Shadab Husain, Mohammad Shadab Sheikh 5th semester Mechanical Engineering Student, Anjuman college of Engineering and technology Nagpur, India

6. Singh Pankaj, Surve Qais, Sayed Saif, Sayed Jafar, Shaikh Nadeem B.E. Mechanical, H.J. Theem College of Engineering Boisar, Maharashtra, India

7. Soakakke, Harsil Yadev Design and Fabrication of automatic Can Crusher

8. Suryakant D. Thakur, Akshay B. Patel, Nitin K. Tilekar, Akash B. Wagh Department of Mechanical Engineering, MET's Institute of Engineering, Bhujbal Knowledge City, Nashik, Maharashtra, India

9. Vishal N. Kshirsagar, Dr. S.K. Choudhary, Prof. A.P. Ninawe. MTech. (pursuing) Mechanical Engineering Department, KDK College of Engineering Nagpur, Maharashtra, India 